\title{
Tiered Mentorship Experiences in Biomedical Engineering Programs: A Case Study of Collaborations between Undergraduates and High School Students
}

\section{Ms. Catherine Langman, Illinois Institute of Technology}

Catherine Langman is a graduate student in applied mathematics at the Illinois Institute of Technology. She is currently a research assistant on a tissue engineering project. She holds a B.S. in applied mathematics from the Illinois Institute of Technology and is a certified secondary mathematics teacher in the State of Illinois. She enjoys working with middle and high school students.

\section{Prof. Eric M Brey, Illinois Institute of Technology}

Professor Eric Brey is a Professor of Biomedical Engineering and co-Director of Distinctive Education in the Armour College of Engineering at the Illinois Institute of Technology.

\section{Dr. Judith S Zawojewski, Illinois Institute of Technology}

Dr. Zawojewski received her B.S. Ed. from Northwestern University, M.S. Ed. from National College of Education (now National-Louis University) and her Ph.D. from Northwestern University. She recently retired as Associate Professor Emerita from Illinois Institute of Technology in Chicago, and in semiretirement joined the University of Chicago Center for Elementary Science and Mathematics Education as a Senior Curriculum Developer. She recently served on the Board of Directors for the National Council of Teachers of Mathematics and on the Editorial Panel for Mathematics Teaching in the Middle School. She has published in numerous teaching and research journals, and written books and book chapters for both mathematics and engineering educators. In addition, Dr. Zawojewski has long been active in writing curriculum related to problem solving. mathematical modeling, and performance assessment. Dr. Zawojewski is especially interested in the role of modeling and problem solving in developing mathematical capabilities, and in enhancing mathematics education for all students. 


\title{
Tiered Mentorship Experiences in Biomedical Engineering Programs: A Case Study of Collaborations between Undergraduates and High School Students
}

\begin{abstract}
Student engagement in STEM fields can occur through exposure to leading-edge research in the field of interest, researching or contributing to the research of others within the field, and communicating that research to others outside of the field. Mentorship is one way to help both students and mentors maintain engagement in these fields. Though some research exists about mentorship between professors and undergraduates, understanding of the relationship between undergraduates who mentor high school students in STEM fields is less developed.
\end{abstract}

In an attempt to further explore the mentor relationships between undergraduates and high school students, this study reports on one aspect of a tiered-mentorship program within a biomedical engineering summer undergraduate research experience. Undergraduates in the biomedical engineering summer research experience and high school students in a summer engineering-themed enrichment program were linked for a week-long program-within-aprogram, whereby the undergraduates acted as temporary mentors to the high school students. In this program, the undergraduates communicated their summer research experiences and broader educational experiences to the high school students. This included presenting their research, guiding lab tours, modeling experiments, accompanying the high school students on a field trip to a topically-relevant museum and corporate site, and collaboratively creating learning activities about key topics in biomedical engineering. Finally, the undergraduates and high school students visited an area summer program for middle school students to present their activities and teach the middle school students about key topics in biomedical engineering.

Three data sources were collected for this study, including semi-structured exit interviews and surveys administered to all of the undergraduates and a sample of volunteers from the high school students who participated in the collaborative program. Data was analyzed using the grounded theory methodology. When examining the nature of the interactions between the undergraduates and the high school students, two dominant themes emerged: (1) the "Influence of a Near-Peer", and (2) Teaching and Learning. This study categorizes these themes and provides examples of evidence of the same.

This collaboration and following study were the result of a combined effort between a National Science Foundation-funded Research Experience for Undergraduate program (the "REU Program" at a university in the Midwest) and a summer engineering-themed program for high school students entering 11 th and 12th grade in the same city with combined sponsorship from a corporate partner and the same university (the "H.S. Program"). The National Science Foundation only provided funding for the REU Program, whereas the corporate partner and university jointly provided funding for the H.S. Program through an entirely separate grant. The H.S. Program provided the costs for transit, meals and admission tickets for parts of the collaboration between the REU Program and H.S. Program. The middle school program is a 
summer program for children in grades K-6 operated by a local part district. The middle school program voluntarily hosted the undergraduates and high school students as they presented their collaboratively-developed activities but provided no contribution to the cost of the collaborative program.

\section{Background}

Mentorship is by not a new phenomenon, though for over twenty years the concept of mentorship has tended to focus on the undergraduate experience as mentored students rather than as mentors providing guidance to high school students ${ }^{\mathrm{i}}$. While literature exists about tiered mentoring systems in a variety of fields ${ }^{\mathrm{ii}}$, as well as assessment of learning outcomes achieved by these mentorship experiences, there exists less research specifically pertaining to the experience of undergraduates mentoring high school students in STEM-related fields.

\section{Description of the REU Program}

The urban-based Midwest research university has delivered a Research Experience for Undergraduate (REU) program since 2006. For 10-weeks in the summer approximately $10-16$ undergraduate students participate in this program. Students are paired with a faculty member based on project rankings, student background, academic level and experience. Participating faculty are from a variety of departments, including Biomedical Engineering, Chemical Engineering, Mechanical Engineering, Biology, Chemistry, and the School of Medicine, with research centered around diabetes. Diabetes is a complex, pathologic condition, and addressing the disease requires a diverse set of approaches from fundamental understanding of disease pathology, disease management and treatment either of the disease directly or one of its many complications. The students' research projects are developed from ongoing work in the laboratories. The research projects of the undergraduate students covered a diversity of topics related to diabetes, including metabolic engineering, biomaterials, biosensors, medical imaging and tissue engineering. In addition to conducting research, students participated in weekly seminars on topics related to diabetes (basic research, clinical treatment public health and policy), weekly ethics seminars, and off-campus tours of research and clinical facilities. These activities were designed to expose students to the broad health implications of the disease and the importance of research related to the treatment and potential cures for this disease and its complications.

A major focus of this program is on tiered-mentorship, whereby graduate students also mentor the undergraduates. In the model of graduate student mentors, the graduate student and undergraduate have periodic meetings with the faculty member to report their progress and discuss data/results. Depending on the structure of the laboratory, the undergraduate student either works directly with the faculty member or the faculty member assigns a graduate student to work with the undergraduate student. Under the guidance of the faculty member or faculty member/graduate student, the undergraduate students conduct a research project focused on engineering approaches to study the treatment of diabetes or its complications. 


\section{Description of the High School Students' Program}

Founded in 2011, the program for high school students (the "H.S. Program") is a free, two-year academic enrichment program that inspires high-achieving, urban-area high school students to make a difference in their communities through STEM and to pursue higher education. The H.S. Program admits students during their sophomore year for participation beginning the summer before their junior year of high school. Students who enroll in the H.S. Program make a two-year commitment to the program, and the H.S. Program serves approximately one hundred total juniors and seniors at any time. Each summer, the H.S. Program begins with a four-week, nonresidential session of STEM-related programming (the "Summer Program"). In addition to the Summer Program, the H.S. Program offers workshops, field trips, career exploration opportunities, and college advising during the school year.

A major goal of the H.S. Program is to foster a sense of community among the admitted students and to introduce the high school students to a variety of people studying STEM fields and working in STEM fields in different capacities. To further this goal, the Summer Program includes a variety of eight-day collaborative projects in a variety of STEM-related fields. Students are allowed to choose one of those eight-day collaborative projects to join with their peers. The focus of these eight-day projects is to collaborate with a community partner to learn about STEM-related topics and then use that new knowledge to create and share a "deliverable" to a predetermined audience. The collaboration between the REU Program and Summer Program is one of these eight-day projects. As both the REU Program and H.S. Program focus on fostering a sense of community among their participants to encourage further study in the STEM fields, the REU Program volunteered to organize one of the eight-day project options for high school students in the Summer Program. The collaborative program was designed to give the high school students a glimpse of life in biomedical engineering school and to enhance the teaching and leadership skills of the undergraduates.

\section{Design of the Collaborative Program}

The objective of the partnership between the REU Program and the Summer Program focuses on developing tier-mentorship experiences for both groups. A separate facet of the REU Program includes mentorship from graduate students who actively contribute to the development of the undergraduates in the REU Program. By including high school students as a group with whom the undergraduates can interact, the undergraduates gain the experience of acting as a mentor, in addition to being mentored. Similarly, by introducing the high school students in the Summer Program to undergraduates who are actively pursuing a field of study in which the high school students expressed an interest, the high school students gained a mentor who had valuable information about the college experience and, in particular, the experience of a biomedical engineering student to share.

The collaborative program was piloted during Summer 2012, revised, and tested again with a new cohort of REU students and high school students in the Summer Program during Summer 2013. The structure of the collaboration during both summers was similar in certain ways. During both Summer 2012 and Summer 2013, the REU students taught the high school students about their research, conducted lab shadowing days, and collaborated with the high 
school students to create activities to teach middle school students about diabetes and related biological processes.

Changes that were made for the Summer 2013 collaboration included the addition of field trips to a topically-relevant surgical history museum and a tour of a consulting firm that involves work in biomedical engineering. Also, before meeting the undergraduates during the Summer 2013, the high school students spent the first two days of the collaborative program engaged in activities related to key topics in biomedical engineering, including scale and measure, mathematical modeling, angiogenesis, wound healing, and diabetes, to help prepare them for the week ahead.

This collaborative program also represents research collaborations between a professor of biomedical engineering and a graduate student studying mathematics education. The professor of biomedical engineering served as the lead faculty organizer of the REU Program, and the graduate student served as a program instructor for the high school students who collaborated with the professor of biomedical engineering to structure the collaboration between the high school students and undergraduates. Through interviews and surveys with the undergraduates and high school students, we collected data about the collaboration and used that data to deduce certain themes that emerged as important to the experiences of the undergraduates and high school students. This study reports on those themes to further the research on how these collaborations can be fostered and to deduce what practices and models are beneficial to fostering these relationships.

\section{Samples}

This study identifies samples from the undergraduates admitted to the REU Program for the 2012 cohort and the 2013 cohort and from the high school students admitted to the H.S. Program for the Summer 2013. There were a total of thirteen undergraduate students who participated in the REU Program in 2012. Of the thirteen, eleven attended four-year institutions and two attended two-year community colleges. There were a total of sixteen undergraduate students who participated in the REU Program in 2013. Of the sixteen, fourteen attended fouryear institutions and two attended two-year community colleges.

An overview of the students admitted to the H.S. Program describes the students as coming from a wide variety of backgrounds. A total of 106 students were admitted for the 20132014 cohort, including 77 juniors and 29 returning seniors. The majority (approximately 85\%, as reported by the H.S. Program) of the students from the 2013-2014 cohort were from the local urban public school district or its affiliate charter schools, with 43 different high schools represented. The majority of those students come from populations underrepresented in the STEM fields.

There were a total of 15 high school students who participated in collaboration with the REU Program during the Summer 2012. There were a total of 32 high school students who participated in the collaboration with the REU Program during the Summer 2013. These 32 high school students attended 26 different high schools. Of these 32 students, we captured data from ten of these students, who volunteered to be part of the sample. 


\section{Data Collection}

Three separate data sources were analyzed in this study. One data source consisted of post-program surveys and semi-structured exit interviews were administered to all of the REU students in the 2012 cohort. The post-survey for the 2012 cohort included the questions: (1) What experiences did you share with the high school students?; (2) In general, describe what you gained from working with high school students who are considering careers in STEM fields.; and (3) In general, describe what the high school students gained from working with college students (including yourself) who are participating in the REU program. The semi-structured exit interviews involved an interviewer asking the undergraduates to generally describe their experiences with the high school students.

A second data source was semi-structured exit interviews administered to all of the REU students in the 2013 cohort. The semi-structured exit interviews involved an interviewer asking the undergraduates to describe their experiences with the high school students.

Finally, the third data source was semi-structured interviews administered to ten of the high school students in the 2013 cohort. The semi-structured interview included four questions about the high school students' experiences, including: (1) What experiences did you share with the undergraduates in the summer research program?; (2) Describe what you gained from working with the undergraduates in the summer research program.; (3) Describe what you think the undergraduates gained from working with you.; (4) Describe what you gained from working with the middle school students. The semi-structured interviews involved an interviewer asking the high school students to describe their overall experiences in the collaborative program.

\section{Methods}

The constant comparative method was used to analyze the survey and interview data. This method of analysis was developed by Glaser and Strauss in 1967 as a process to understand what participants see as being significant and important in their experiences, which forms the basis of grounded theory iii. Grounded theory may be defined as "the discovery of theory from data systematically obtained from social research,i. Charmaz ${ }^{\mathrm{iv}, \mathrm{v}}$ identifies a number of features that all grounded theories have: simultaneous collection and analysis of data; creation of analytic codes and categories developed from data and not by pre-existing conceptualizations; and discovery of basic social processes in the data.

Following this method, data were collected in the form of semi-structured exit interviews, which were recorded and transcribed. The transcripts revealed participants' descriptions and explanations of their experiences in the collaborative program. These transcripts were then coded with internal codes (derived from the data).

Coding the data obtained from transcripts of the interviews occurred in three stages: (1) identifying and classifying participants' descriptions of the collaborative program and their role in the collaborative program; (2) coding the explanations while, in particular, annotating descriptions of the situation, circumstances, interactions, general conditions or experiences, and 
practices that occurred; and (3) characterizing the explanations. These stages are based on qualitative methods described by Strauss and Corbin. The third stage involved multiple iterations of developing codes, applying them, searching for inconsistencies, and redefining and reapplying the codes to establish a stable coding system, and ultimately, high levels of coding consistency. Then, finally, frequencies of occurrences were examined to search for patterns, which became the dominant themes described herein.

Though the transcripts were provided by two different cohorts of undergraduates and one cohort of high school students, the goal of the research was to look broadly at the effect of the collaborative program across these different groups. Therefore, the data from these groups were analyzed simultaneously.

\section{Results}

Based on the data collected from interviews and surveys, two interrelated themes emerged from the data: THE INFLUENCE OF A "NEAR-PEER" and TEACHING AND LEARNING.

In total, there were 156 units of data from the interviews with all REU participants that were deemed relevant to the research question. At the theme level, 99 units of data $(63 \%$ of the total units) were placed in the INFLUENCE OF A "NEAR-PEER" theme and 57 units of data (37\% of the total units) were placed in the TEACHING AND LEARNING theme. The frequencies were calculated to determine how much the undergraduates from both cohorts emphasized certain aspects of the collaborative program.

Separately, there were 21 units of data from the interviews with the high school students in the 2013 Summer Program. At the theme level, 13 units of data (62\% of the total units) were placed in the INFLUENCE OF A "NEAR-PEER" theme and 8 units of data $(38 \%$ of the total units) were placed in the TEACHING AND LEARNING theme.

\section{The Influence of a "Near-Peer"}

Relationships between individuals who are in adjacent stages in life - for example, a high school junior and a college junior - can offer certain insights and experiences that would otherwise be unattainable for either group. The INFLUENCE OF A "NEAR-PEER" theme was observed through descriptions of the undergraduates providing the high school students with information and opportunities related to both the study of engineering and college in general and through descriptions where the high school students identified that this information was provided to them. In both the 2012 and 2013 REU cohorts and in the 2013 Summer Program cohort, the influence of someone relatively close in either experience or age providing guidance about college in general and STEM-related fields in particular emerged an important aspect of the collaborative program. Interestingly, the REU cohorts more frequently cited age as the difference between themselves and the high school students, rather than experience, at a ratio of approximately $4: 1$, through the context of the discussions emphasized that the key difference was experiential. 
The INFLUENCE OF A "NEAR-PEER" theme is captured in two different categories of responses. The first category relates to the college experience in general and the second category relates to the specific experience of a student in biomedical engineering.

First, the REU students used a first-person, empathic view of the high school students' experiences in the program by providing college guidance in general to the students, as illustrated by the following interview quote from one REU student:

REU: It felt good to see that someone else was getting guidance, because I remember when I was in their position, I didn't feel like I had much guidance about going to college and what should I worry about as far as what's a good school and where to apply.

The high school students mirrored this response when asked the question, "Describe what you gained from working with the undergraduates in the summer program," as illustrated by this response from one high school student:

High School Student: I didn't know much at all about what being an undergraduate student was like or what it involved. I thought it was very interesting how much freedom they were given in their studies. It was helpful to be able to see thing through their perspectives instead of just my own.

Echoed another high school student:

High School Student: I was able to see what being in a college lab is like and am able to use this experience to plan my future in school.

Second, the REU students felt that having someone showing the high school students a practical, interesting application of the theoretical knowledge learned in early undergraduate study was beneficial for the high school students' growth and development. As illustrated by the interview with one REU in the 2013:

REU: After showing them the project, I made a point of telling them this-this-and-this have to do with this project and without those things, I couldn't do this project. After if I'd heard that, even as a freshman in college, I would have been even more motivated.

The high school students provided parallel responses to this category: High School Student: I was happy to be able to see some of the cool things BMEs (Biomedical Engineers) and BME majors get to do on a daily basis, and would love to see more of it, and even work with them.

\section{Teaching and Learning}

The TEACHING AND LEARNING theme related to the approaches used by the undergraduates to teach the high school students about their research, the high school students' responses to the undergraduates' efforts to teach them about their research, and the collaborative effort to teach middle school students about key topics in biomedical engineering. Within the TEACHING AND LEARNING theme, three categories emerged. 
First, within this theme, the undergraduates described the approaches and strategies they took to communicate their research to the high school students and the high school students described their approaches and strategies they took when communicating to the middle school students. Specifically, the undergraduates and the high school students both emphasized the importance of "preparation" and "anticipating questions" related to their own understanding of the subject matter. Many of the undergraduates admitted "surprise" at the level of questions asked by the high school students during the lab shadowing and in other interactions. As described by an REU student about teaching the high school students:

REU: I enjoyed teaching them. At first, I was-for lack of a better term-I was nervous, because I didn't know what questions they were going to ask, and I was second-guessing what I knew. So I brushed up on everything I knew. And then they came, and I told them about my research, and they would ask questions that I could answer right away without a second thought... And it helped me a lot with my confidence that I knew my stuff.

Amongst both cohorts of REU students, enjoyment of teaching the high school students about their research was the most commonly reported positive consequence of working with the high school students.

The high school students made similar comments, including this quote regarding the high school students' teaching a group of middle school students about wound healing and diabetes:

High School Student: In order to teach them, we had to really know exactly what we were talking about. They helped us to understand the subject through our explanation and their questions.

Second, within the TEACHING AND LEARNING theme, communication played a crucial role in the relationships between the undergraduate students and high school students, as well as between the high school students and middle school students. Both groups described the importance of using "simple analogies" and "simplifying the complex" when teaching and the resultant learning the occurs for the party in the teaching role, as illustrated by this quote from an REU student speaking about teaching the high school students:

REU: I thought it was a good thing for me and for them, because I participated in sharing my research with them and had to think of breaking it down to the point where they could understand it. It was challenging but at the same time it was a good experience because if I could teach them what my research is like, then I'm pretty sure I could break it down for anyone.

The high school students made similar comments about teaching the middle school students, including:

High School Student: I realized that you have to put things in even more simple terms than the undergraduates had done for us so that they could understand the topic. I was able to see that using simple analogies actually helps!

Finally, a category that emerged within the teaching and learning theme involved what each group thought that the other group learned through the collaboration and comparisons between what the two groups learned. For example, when prompted to "describe what you think 
the undergraduates gained from working with you", the high school students responded that "they gained a sense of how to explain things to people who don't necessarily understand." In semi-structured interviews, which did not contain the prompt, the high school students still volunteered their thoughts that the undergraduates gained a valuable experience working with them, though tempered with comments such as "I know I gained way more than the undergraduates earned from working with me, but they learned some things from me, too." Evidenced by one high school student:

High School Student: I know they gained another perspective on how students think. I know they were able to gather more information of how teaching can affect certain students differently than others.

Likewise, the REU students believed that the interactions they had with the high school students offered the high school students a "unique opportunity" that exposed the high school students to "things they'd probably never seen" and commented that "it was really interesting to see the learning and how excited they were about it". Many of the REU students in the 2013 cohort reported positive feelings about the overall program, specifically emphasizing that seeing the high school students learn felt good to the REU students. Several of the REU students commented that they began more interested in pursuing teaching as part of a career option in the semi-structured interviews.

\section{Discussion}

The findings of this small, qualitative study provide a glimpse into the interactions between undergraduates and high school students in a summer engineering-themed collaboration. From the perspective of both the undergraduates and the high school students, there were two main themes that emerged from this collaboration - the INFLUENCE OF A "NEAR-PEER" and TEACHING AND LEARNING.

The INFLUENCE OF A "NEAR-PEER" related to the undergraduates providing the high school students with guidance about college in general and biomedical engineering studies specifically, as well as modeling the behaviors of an undergraduate student in a summer research program, and the high school students' observations of and responses to these aspects of the interactions. The TEACHING AND LEARNING theme related to the teaching approaches taken by the undergraduates to teaching the high school students and the high school students to teaching the middle school students to communicate ideas and concepts in biomedical engineering, the communication strategies taken by both groups when teaching, and the thoughts and observations of each group on what the other group had learned through the collaboration.

Interviews with the undergraduates and the high school students helped identify these subcategories. Some limitations of this study include the sample size and the study design. Since no responses were obtained from the high school students who participated in the 2012 collaboration and fewer than all high school students participated in 2013, the sample representing the high school experience in the collaboration was not fully representative of the whole group of participants. Also, though the analysis of data was done by a different researcher than the researcher who initially conducted the interviews, it is possible that the semi-structured nature of the interviews influenced responses of the study participants. Though our analysis did 
not reveal any obvious biases as a result of the semi-structured nature of the interviews, a redesign of the interview process could help ensure that bias is mitigated.

Future data collection and analysis is necessary to provide a more sophisticated approach to gathering and categorizing the high school students' and undergraduates' responses. Some of these approaches might include a redesign of the interview process to attempt to identify and minimize any interviewer bias that may emerge in the data. Long-term effects of the collaboration, including any influence on the career or academic goals of the high school students or undergraduates as a result of the collaboration, would require additional data collected at dates into the future.

Further, despite the findings that the undergraduates and high school students used teaching strategies during the collaboration, the data collected provides no evidence of the effectiveness of these strategies, in terms of learning outcomes for the individual students. However, this was not the primary focus of this study.

Finally, this study has the potential to influence existing and future undergraduate research experiences in several ways. First, by incorporating high school students and middle school students into the tiers of the research experience, the undergraduates develop mentoring experience that is not a typical component of many undergraduate research experiences. Second, the high school students gain access to "near-peers" who provide a window into research experiences that would otherwise be completely obscured from the high school students' experiences. This could encourage more high school students to pursue biomedical engineering or other STEM disciplines with an eye toward research.

\section{Bibliography}

\footnotetext{
${ }^{\mathrm{i}}$ Jacobi, M., Mentoring and Undergraduate Academic Success: A Literature Review. Review of Educational Research, Vol. 61, No. 4 (Winter, 1991), pp. 505-532

${ }^{\text {ii } K m a n, ~ N . E ., ~ B e r n a r d, ~ A . W ., ~ K h a n d e l w a i, ~ S ., ~ N a g e l, ~ R . W ., ~ \& ~ M a r t i n, ~ D . R ., ~ A ~ T i e r e d ~ M e n t o r s h i p ~ P r o g r a m ~}$ Improves Number of Students With an Identified Mentor, Teaching and Learning in Medicine: An International Journal, Vol. 25, Issue 4 (2013), pp. 319-325

iii Glaser, B.G. and Strauss, A.L., The Discovery of Grounded Theory. (Aldine, 1967)

${ }^{\text {iv }}$ Charmaz, K. 'Discovering' chronic illness: Using grounded theory. Social Science and Medicine 30(11):11611172 (1990)

${ }^{v}$ Charmaz, K. Constructing Grounded Theory: A Practical Guide through Qualitative Analysis. London Sage Publications. (2006)
} 